\title{
Focus in Honor of Fred McLafferty, 2003 Distinguished Contribution Awardee, for the Discovery of the "McLafferty Rearrangement"
}

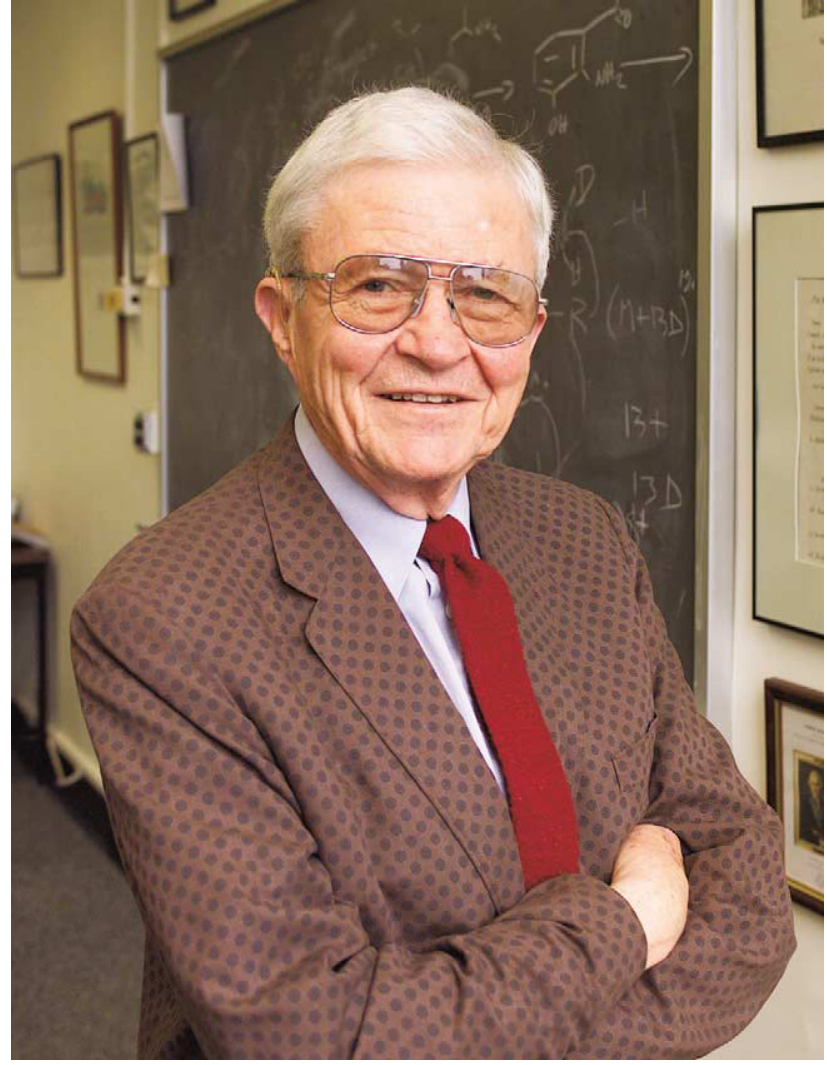

Figure 1. Fred McLafferty today.

Fred McLafferty (Figure 1), one of the towering figures in mass spectrometry began his career with the discovery of the rearrangement that came to be known as his reaction, although he often and modestly refers to it as the " $\gamma-\mathrm{H}$ rearrangement to an unsaturated group with $\beta$-cleavage," a title that does not readily "roll off one's tongue." For this accomplishment, Fred received the 2003 Distinguished Contribution in Mass Spectrometry Award of the American Society for Mass Spectrometry. JASMS, the society journal, is pleased to dedicate a Focus issue to Fred to commemorate the award and offer to Fred our congratulations.

Fred and I share a common background in a way that you would not expect. Although I was one of his early postdoctoral students at Purdue, it's not the Hoosier State of Indiana that provides the link, but rather the Cornhusker State of Nebraska.

Published online June 11, 2004

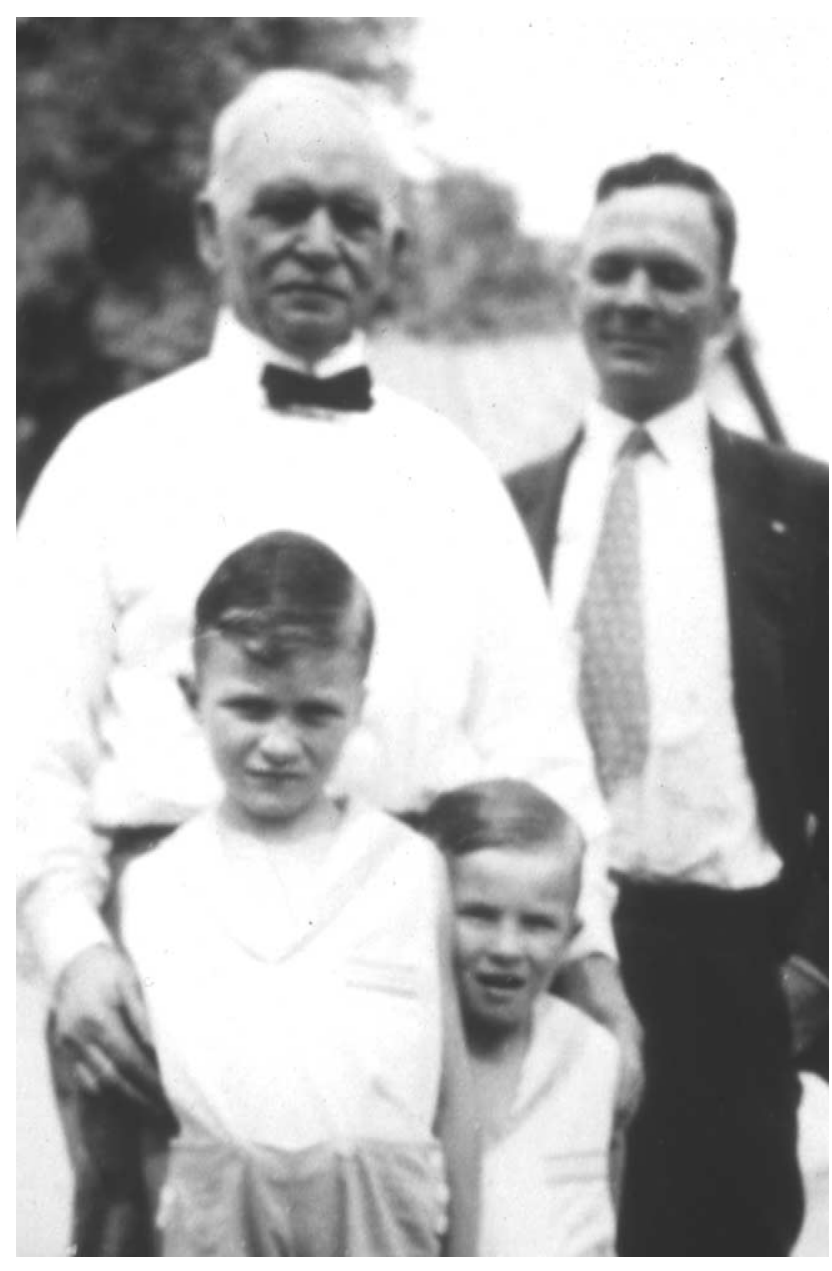

Figure 2. Fred (left foreground) in $\sim 1930$ with brother Charles, his grandfather, and his father.

Both of us spent over 20 years in that state; Fred as a young boy and as an undergraduate and Master's student at the University of Nebraska and I as a member of that faculty some years later. World War II interrupted Fred's studies, but after serving on the German front, Fred returned to Lincoln where he completed his MS degree. Our common background plus invitations by Fred to represent (roast) him at his retirement symposium and at his 80th birthday party in 2003 gave me the motivation to research his background. Records in the Department of Chemistry at Nebraska were especially informative about Fred's early days prior to the discovery of the rearrangement. 


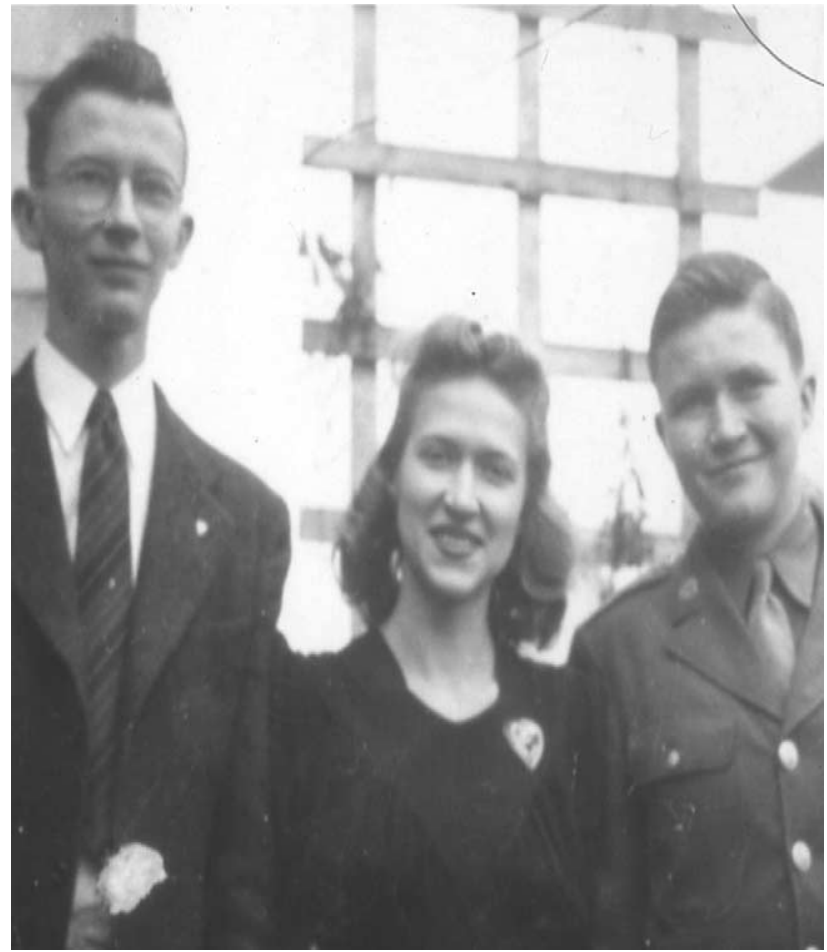

Figure 3. The McLafferty siblings, Charles, Lucy, and Fred (in his U.S. Army uniform).

Fred was born in Evanston, Illinois, but went to grade school in Omaha and in Nuckolls County, Nebraska. He graduated from Omaha North High School in 1940. In Figure 2, we see Fred, who is not difficult to recognize, and his, brother, father, and grandfather. His great grandfather was J. Warren Keifer, speaker of the U.S. House of Representatives from 1881 to 1883, a man who was said to have a "combative personality." Why are we not surprised?

Tom Brokaw, the ABC News Anchor in the United States, who was born the same year as I, described in his book, The Greatest Generation, Fred's generation as the best in American history. They came of age during the Great Depression, fought World War II in Europe and in the Pacific, a war in which moral choices were not ambiguous, and returned home to rebuild their lives and not only the economy of the U.S. but also those of their former enemies. They married and gave birth to the "baby-boomer" generation. They took advantage of a generous contribution to higher education by the American people. They built a new society and set the stage for today's science and technology.

Fred was very much part of this generation. His B.S. studies at the University of Nebraska were accelerated and completed in 1943 because of the urgency of war and the need to recruit young people to serve in the armed forces. Fred, like so many, accepted the challenge and served on the Western Front during the invasion of Germany. For his efforts and sacrifice, he was awarded the Purple Heart and the Combat Infantry Badge. His physical chemistry laboratory

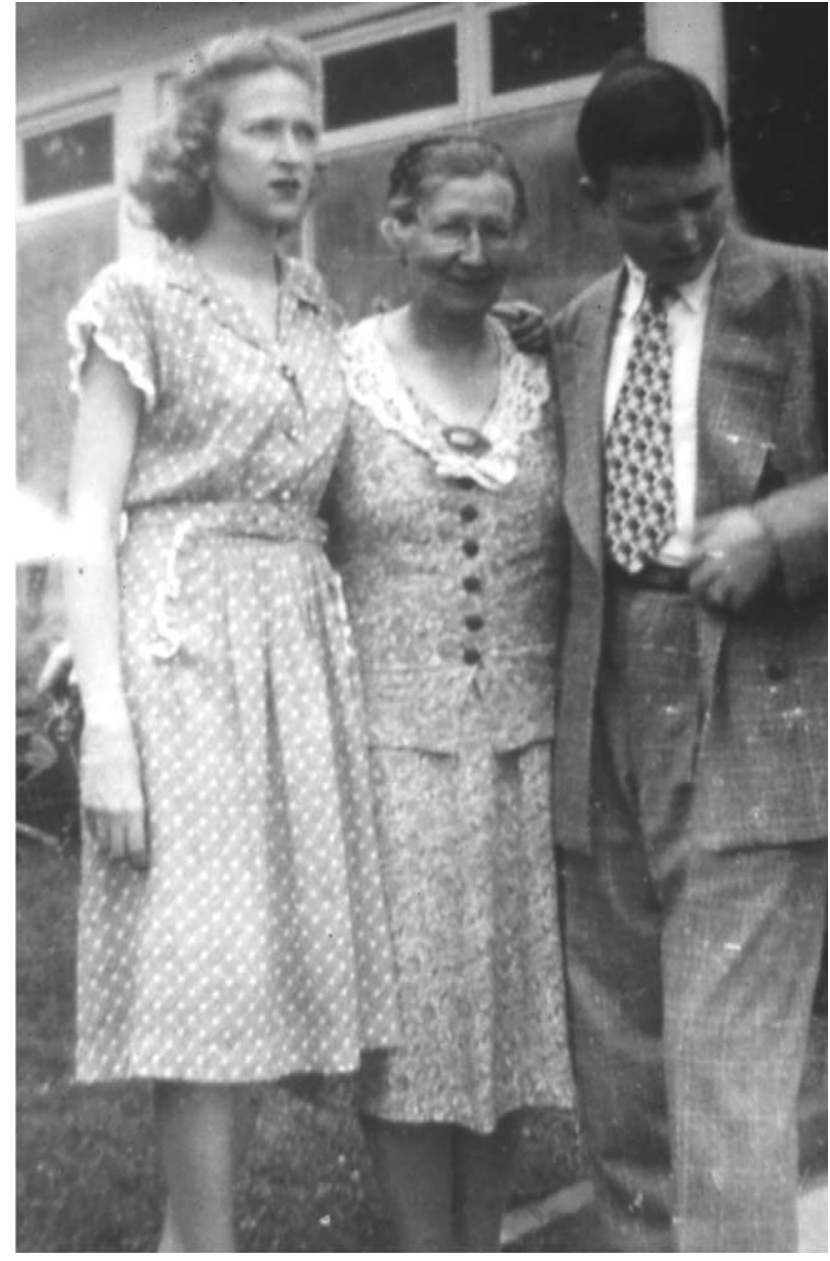

Figure 4. Mother McLafferty and two of her children, Lucy, and Fred, in 1946.

professor, E. R. Washburn wrote on Fred's grade card prior to Fred's service in the war effort: "In the Army-A.S.T.P.—entered the course late-but worked full time nearly every day." In Figure 3, we see Fred with his brother, Charles, and his sister, Lucy, prior to leaving for Europe.

Fred returned to Lincoln, Nebraska, and to the University. He felt he had not done justice to difficult subjects such as Physical Chemistry, and so he reenrolled in that course so that he could improve his understanding of the material through which he had raced prior to the war. The same E. R. Washburn wrote on the physical-chemistry grade card for the fall term in 1945 that Fred had "entered late- on discharge from the Army."

During that time, Fred served as a teaching assistant for Professor H.A. Pagel, with whom he also studied for his M.S. degree. One of his charges in the laboratory of Chemistry 220 was Elizabeth Curley, from Seward, Nebraska, a small town just west of Lincoln. Tibby, as she has been commonly known, later became his wife and mother of their five children.

Fred's M.S. thesis, "Tributyl Phosphate, An Extract- 


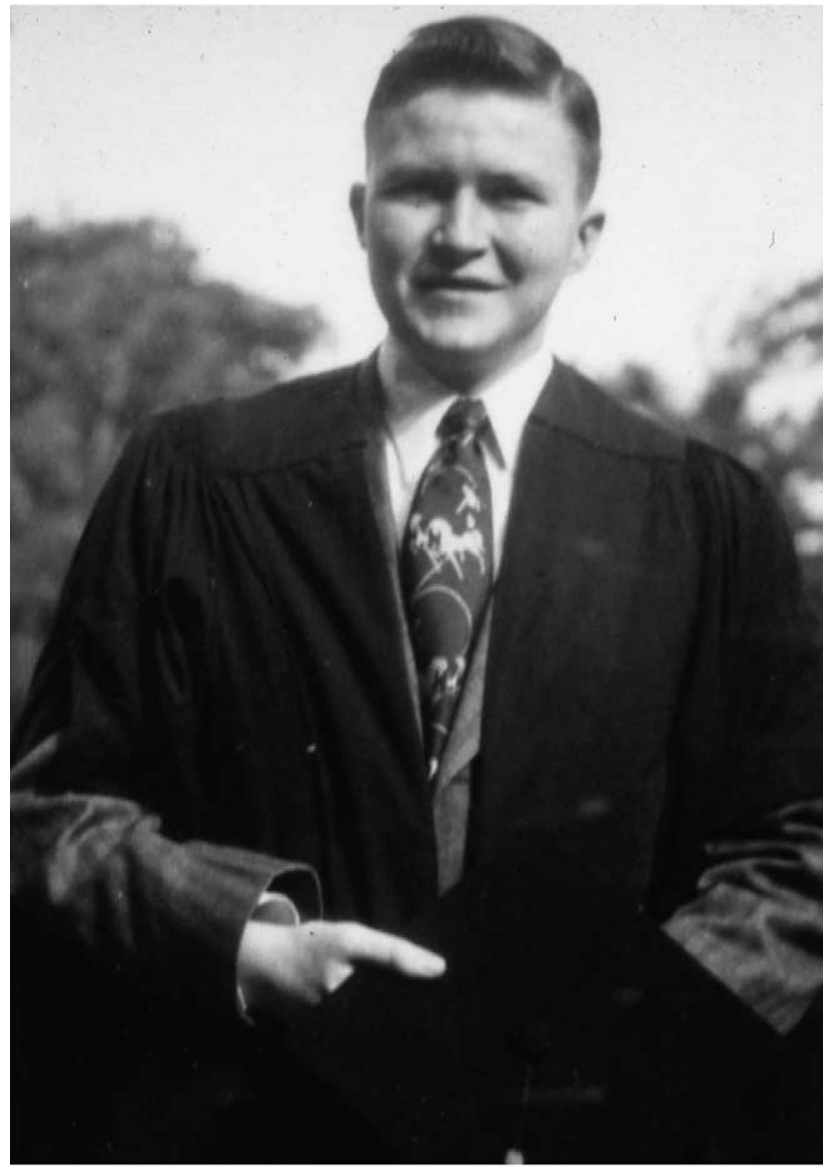

Figure 5. Fred McLafferty on the occasion of receiving his M.S. in chemistry from the University of Nebraska in 1947.

ing Agent for Organic Acids," seems far removed from mass spectrometry and the McLafferty Rearrangement, but this good, solid background in chemical analysis served Fred for his entire career. Fred's work resulted in two publications in Analytical Chemistry in 1948. During those days, Fred lived at 1725 Washington, a few blocks from where I later purchased my first home. In Figure 4, we see Fred, his mother, and sister during their Lincoln days, and in Figure 5, the new MS recipient.

It was time for Fred and Tibby to leave Nebraska and for Fred to work on his Ph.D. degree. Fred chose Cornell University (Figures 6 and 7). Tibby later contrasted Lincoln and Ithaca by noting that "the dances ended at $10 \mathrm{pm}$ in Lincoln and started at $10 \mathrm{pm}$ in Ithaca. . . and there was drinking. .." Fred's Ph.D. mentor, William Miller, later published Fred's thesis work, "Mechanism of fluorination. II. Free radical initiation reactions. Fluorine-sensitized chlorination and oxidation," which appeared in the Journal of the American Chemical Society in 1956.

Upon completion of his Ph.D. studies at Cornell in December, 1949, Tibby and Fred returned to the Midwestern part of the U.S. to do a postdoctoral fellowship with R.L. Shriner at the University of Iowa. Shriner is well known among organic chemists

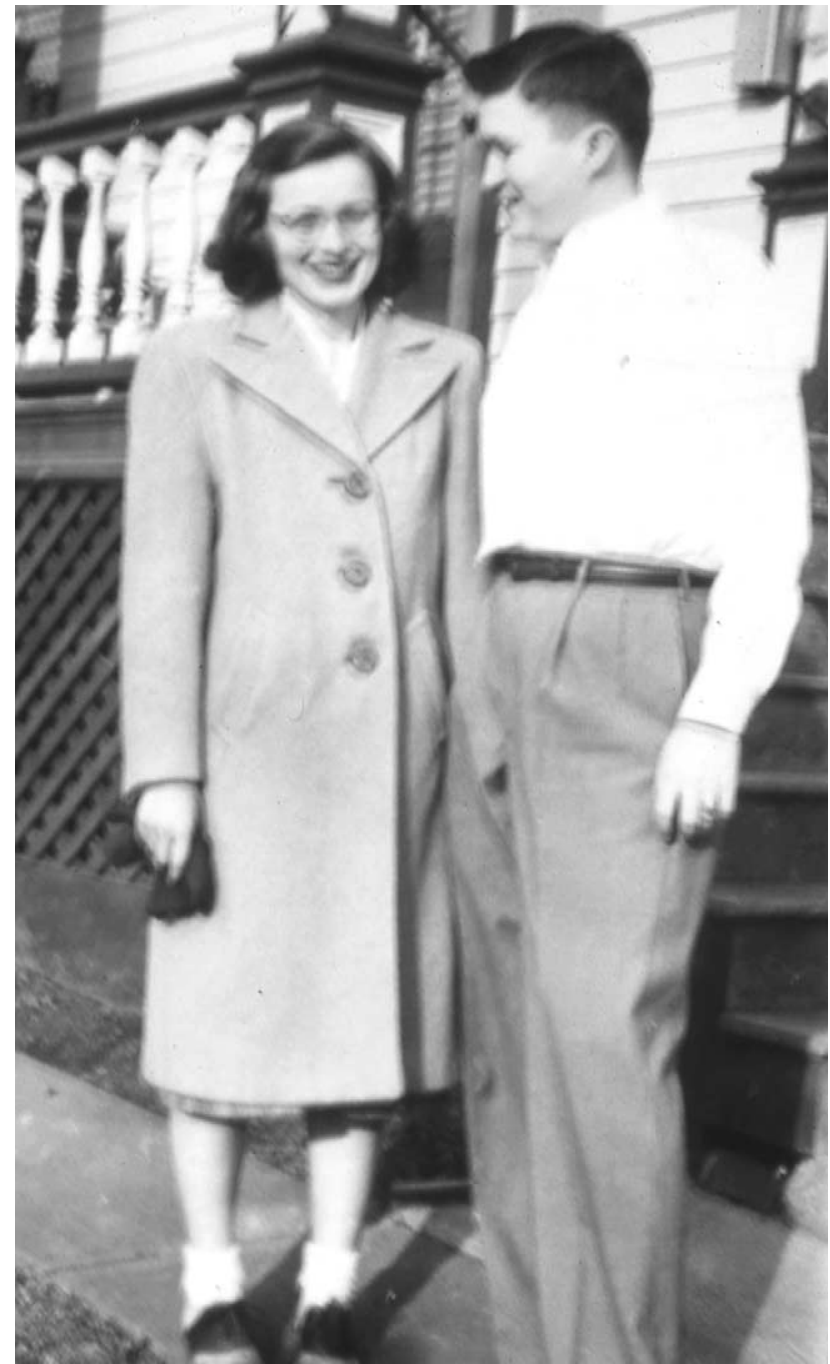

Figure 6. Fred and Tibby in Ithaca, NY, in 1948.

of my generation owing to the book, The Systematic Identification of Organic Compounds by Shriner, Fuson,

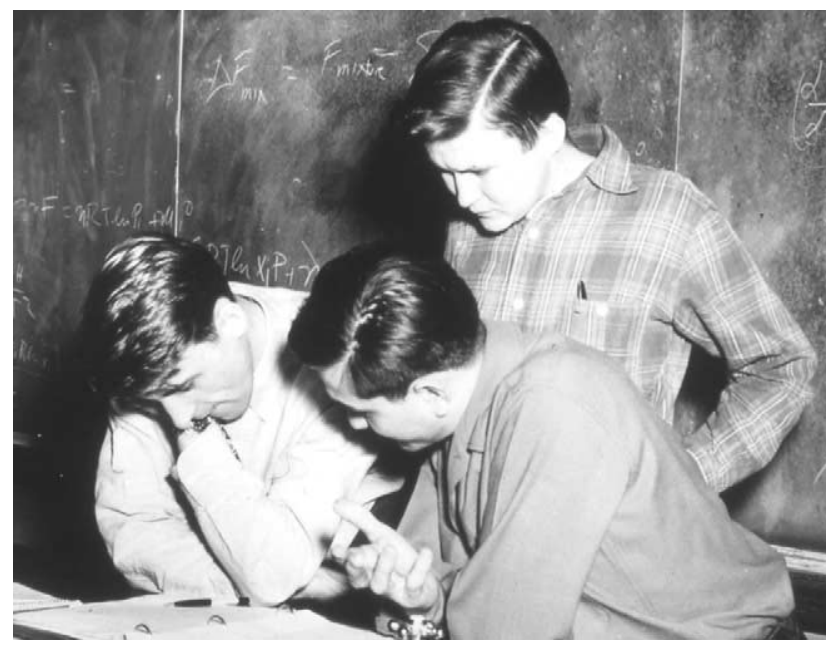

Figure 7. Intense Fred and two graduate student colleagues at Cornell University, in 1947. 


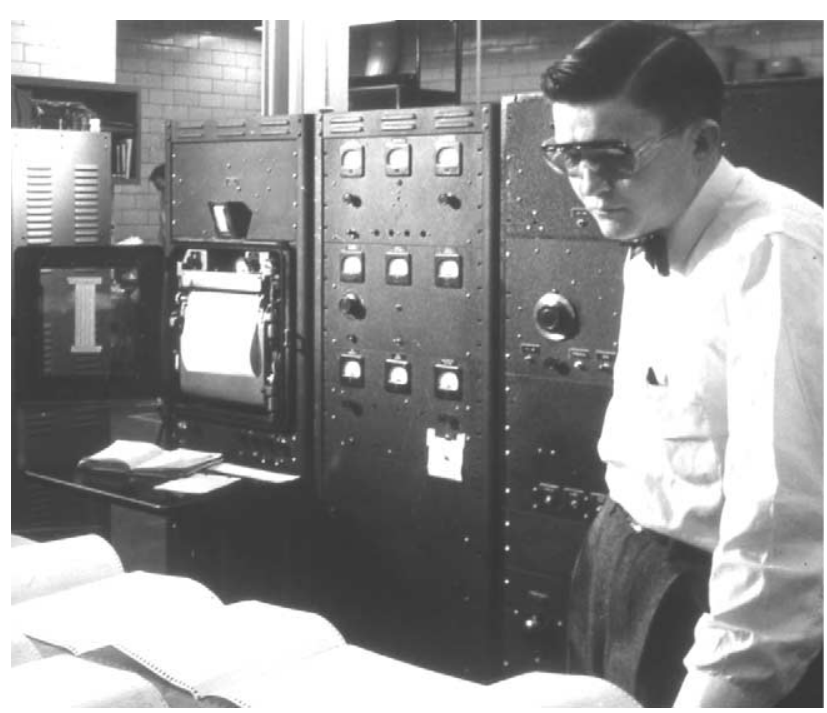

Figure 8. Fred McLafferty working out the details of the rearrangement.

and Curtin, forecasting some of Fred's future interests. Following the short stay in Iowa City, Fred and his family moved to his first "permanent" position at Dow Chemical in Midland, Michigan, where he was in charge of mass spectrometry and gas chromatography from 1950 to 1956. From 1956 to 1964, Fred was the first director of the Dow Framingham Eastern Research Laboratories. These were the halcyon days in chemistry when basic chemical companies maintained extensive, academic-like research laboratories, now a phenomenon of the past.

In 1956, Fred published his first independent article in Anal. Chem. "Mass spectrometric analysis. Broad applicability to chemical research." Clearly, Fred's ideas on the utility and excitement of mass spectrometry were forming already.

This article was soon followed by a classic article, "Mass Spectrometric Analysis. Molecular Rearrangements," Anal. Chem., (1959) 31, 82-87, in which Fred described how one should think about rearrangements in mass spectrometry (Figure 8). Concepts that we use nearly 50 years later are much in evidence; examples are odd- and even-electron ions, specific vs. nonspecific rearrangements, simple cleavage reactions, etc. Some key considerations for the rearrangement, as taken from the article, are quoted below.

"The migration of hydrogen on cleavage of a bond beta to an electron withdrawing group is a prime example of a specific rearrangement, both in the high relative abundance and specificity of the rearranged ions that it yields and in the large number of compound classes in which it is found. ."

"The polar unsaturated groups such as carbonyl. . . thus often give such specific rearranged ions as the largest peak in their spectra. . . A possible general mechanism is shown in the following scheme (from the original article). Thus, the replacement rearrangement
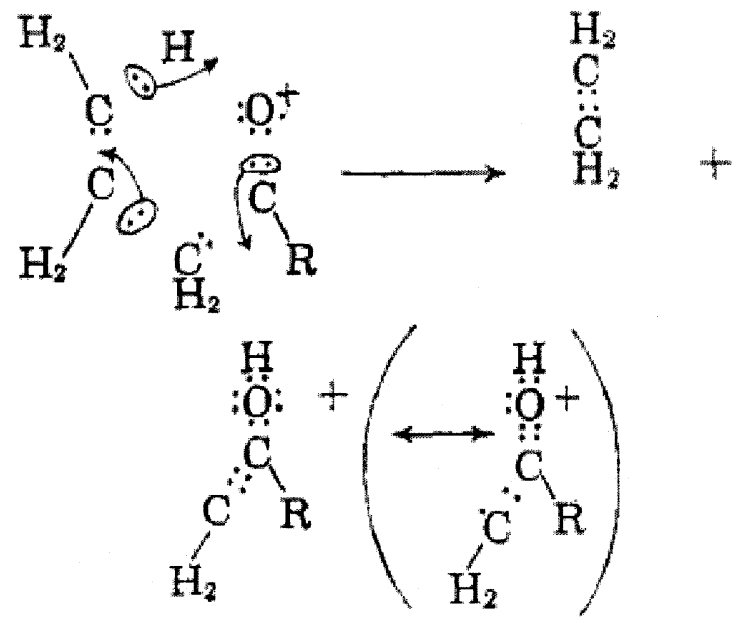

of hydrogen allows the formation of the stable ethylene molecule and the odd-electron ion (here probably of fairly high stability) from the odd-electron molecule ion, with the cyclic intermediate favoring a lowered activation energy."

In 1958, Fred published in Chemistry and Industry a report on the results of isotopic labeling. The abstract of the article reads:

"The mass spectra of isotopically labeled molecules (sec-butyl-2d (I) and sec-butyl-3d acetate (II)) were investigated to shed light on rearrangements on cleavage. The spectra showed that the $\gamma$ - or $\delta$-positions supplied $80 \%$ of the 2 rearranged $\mathrm{H}$ atoms. The spectra revealed that $15 \%$ of the rearranged $\mathrm{H}$ atoms involve 1 of the 2 secondary $\gamma$-H atoms. Thus, the choice of these vs. the other $3 \gamma-\mathrm{H}$ available is either statistical or the $\gamma-\mathrm{H}$ are also involved."

The rearrangement has impact well beyond the specifics of the process. The reasoning that Fred, and others, used in those early days is classic physical organic chemistry, reasoning that was repeatedly used in later decades in studies of gas-phase ion chemistry as that field evolved from one that was originated by chemical physicists.

Ongoing at approximately the same time were some of the first experiments in GC/MS, which were conducted by Roland Gohlke, under Fred's direction. The two pioneering scientists with their GC/TOF mass spectrometer are seen in Figure 9. The first publication by Roland appeared under the title "Time-of-flight mass spectrometry and gas-liquid partition chromatography," Anal. Chem. (1959), 31 535-541.

During these years, the McLafferty family grew with addition of five children: Sally, 1951; Joel, 1953; Martha, 1954; Sam, 1956; and Ann, 1959, causing, we can be sure, other rearrangements in time and energy.

This brings me to the present focus. Usually, focus sections do not occupy an entire volume, but Fred's interests are so broad and his friends and former students so numerous that many persons wanted to 


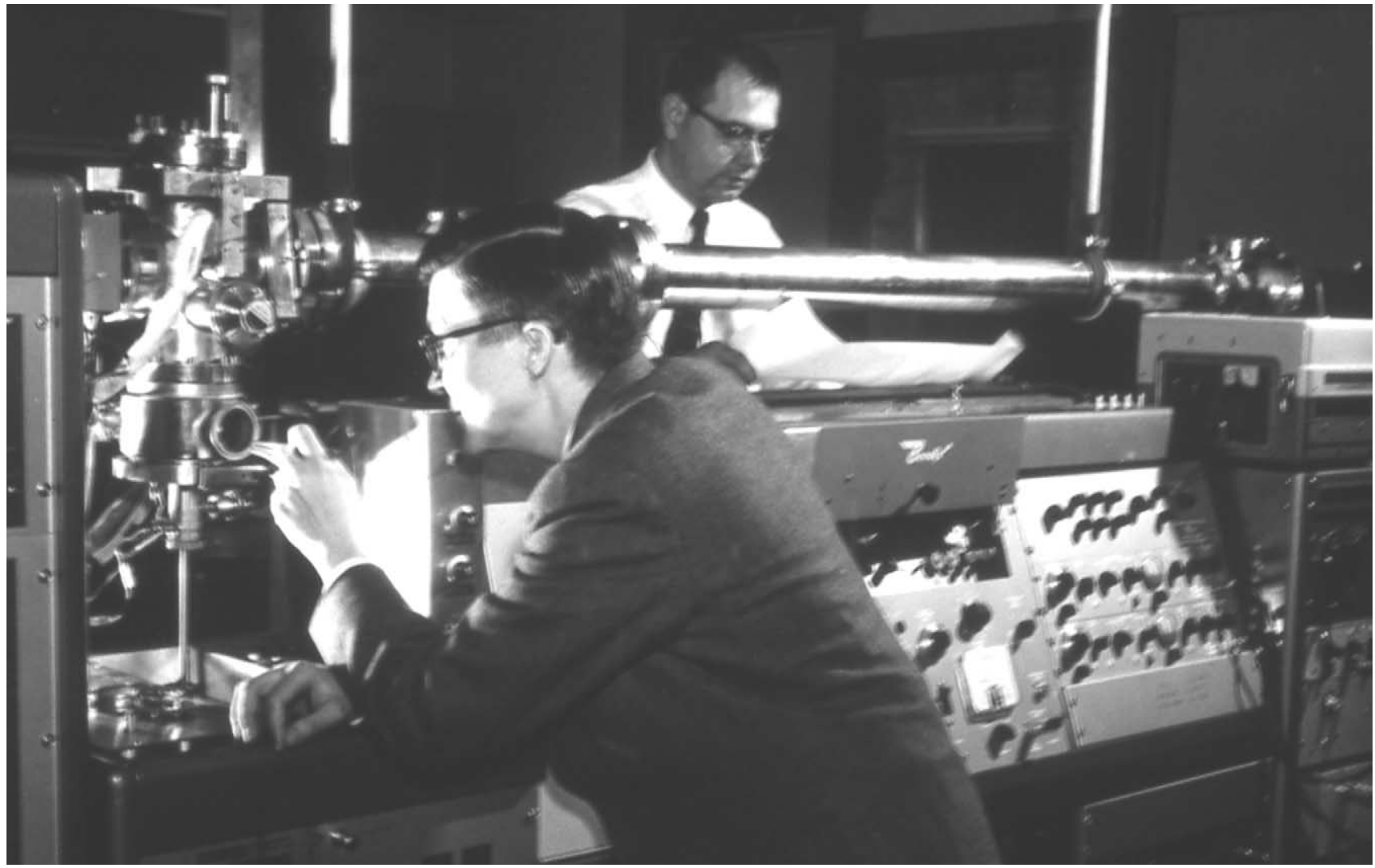

Figure 9. Fred McLafferty (foreground) and Roland Gohlke working on a TOF mass spectrometer at Dow.

contribute. The focus begins, appropriately enough, with a set of articles on ion chemistry. The first is a personal recollection by Nico Nibbering and is followed by a report of a solution analogy to the rearrangement by the Nobel laureate, George Olah. Following are six articles on basic gas-phase ion chemistry by $\mathrm{H}$. Audier, D. McAdoo, E. Uggerud, J. Traeger, R.G. Cooks, and G. Giorgi. This set is followed by descriptions of applications of ion chemistry to biomolecules by E. Williams, C. Wesdemiotis, J. Brodbelt, F. Turecek, G. Sindona, and R. Zubarev. The last three are on various aspects of instrumentation and are by N. Kelleher, P. Todd, and myself. The group of authors spans two generations, many countries, and includes students and friends.

Congratulations, Fred, for the award and thank you for your encouragement and enthusiasm for many years. Your science and, perhaps more importantly, your spirit, have been an inspiration to all of us.

Michael L. Gross

Editor

Washington University 